\title{
REDESCRICุÃO DE ALGUNS EXEMPLARES TIPOS DE ESPÉCIES NEOTROPICAIS DESCRITOS POR FRIESE EM 1899 (APOIDEA, ANTHOPHORIDAE). II. ESPÉCIES EXCLUÍDAS DO GÊNERO TETRAPEDIA KLUG ${ }^{1}$
}

\author{
Jesus S. Moure ${ }^{2}$
}

\begin{abstract}
REDFSCRIPTIONS OF SOME TYPES OF NEOTROPICAI SPECIES DESCRIBED bY FrIFSE (APOIDFA. ANTHOPHORIDAE). II. SPECIES REMOVED From thl: GENUIS TETRAPEDIA KLUG. The following species of Friese's Tetrapedia are removed from this genus to Paratetrapedia pallidipennis (Friese, 1899), Paratetrapedia flaviventris (Friese. 1899). Xanthopedia iheringii (Friese, 1899) and Lissopedia globulosa (Friese. 1899). When necessary lectotypes are proposed and redescriptions provided. Paratetrapedia (Xanthopedia) tricolor Michener \& Moure. 1957, is considered a synonym of Xanthopedia iheringii. and Arhysoceble melampoda Moure, 1948. of Arhysoceble picta (Friese. 1899). These specimens belong to the Zoologisches Museum der Humboldt Universität. Berlin.

KEY WORDS. Apoidea. Paratetrapediini. Paratetrapedia. Xamthopedia. Lissopedia, Arhsocehle. Neotropical
\end{abstract}

Complementando trabalho anterior, removo de Tetrapedia algumas espécies descritas do Brasil por Friese em 1899, passando para Paratetrapedia as espécies $T$. pallidipennis e $T$. flaviventris, para Xanthopedia $T$. iheringii, para Lissopedia T. globulosa e para Arrhysoceble Moure, 1948 T. picta. Lissopedia foi proposto recentemente (Moure 1992), Xanthopedia por MiChener \& MourE (1957) e Paratetrapedia há muitos anos atrás por Moure (1941). Tetrapedia forma atualmente com Lagobata Smith, 1861, a tribo Tetrapediini, dentro dos Exomalopsinae (MiCHENER \& MOURE 1957) tendo ultimamente sido incluido na mesma por Rolg-Alsina (1991) o gênero Coelioxoides, retirado dos Nomadinae.

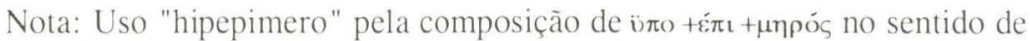
"perna" ou "coxa", com o e longo, ficando uma palavra paroxítona; quando vem de $\mu$ śpos, "parte', como "trímero" a pronúncia é proparoxítona. "Escutoscutelar" resulta da composião de scutum + scutellaris, para a sutura entre o mesoscuto e o escutelo, precedida do "e" eufônico na passagem para o português.

1) Contribuição número 816 do Departamento de Zoologia. Universidade Federal do Paraná.

2) Departamento de Zoologia. Universidade Federal do Paraná. Caixa Postal 19020.81531-990) Curitiba, Paraná, Brasil. Bolsista do CNPq. 


\section{Paratetrapedia pallidipennis (Friese, 1899)}

Tetrapedia pallidipennis Friese, 1899. Ann. k.k. Naturhist. Hofmus. 14 (3): 299.35.

Brasil, Espirito Santo: Santa Leopoldina, exemplar tipo macho, 1897. Em excelente estado de conservação, completo. Designo aqui como Lectótipo, uma vez que Friese cita macho e fêmea.

A descrição original diz: "Testacea, testaceo-hirta, ut michaelis, sed facie grossissime et ruguloso-punctato, tantum occipite obscuro; thorace supra testaceo, nec nigro, opacoque, brevissime testaceo-tomentoso, abdomine toto fuliginoso, apice ferrugineo-setoso. Tetrapedia pallidipennis gleicht der michaelis fast ganz, es ist aber Clypeus und Stirnschildchen sehr grob, fast runzelig punktirt und nur der Scheitel dunkel gefärbt; Thorax oben auch gelblich und ganz matt infolge sehr kurzer, dichter, gelblicher Befilzung; Abdomen ganz braun, das Ende rötlich beborstet, Beine und Flügel wie bei michaelis, nur die Sporen fast weiss. 9-10Mm. lang. $\sigma \mathbf{q}$ von S. Leopoldina (Espirito Santo, Michaelis) Brasilia. (Hierher passt vielleicht auch laevifrons Smith.)"

Macho. Comprimento total aproximado $8,75 \mathrm{~mm}$, da asa anterior $8,75 \mathrm{~mm}$; largura da cabeça $2,8 \mathrm{~mm}$ e do segundo tergo $3,04 \mathrm{~mm}$.

Colorido geral da cabeça, tórax e propódeo amarelo com a fronte (dos alvéolos à tangente ocelar posterior) preta com invasão de amarelo nas paroculares e, acima da supraclipeal até a altura dos três quartos das órbitas: a mancha acima da supraclipeal elíptica, ligada à supraclipeal e afastada do ocelo por uma distância igual à metade do seu comprimento; as das paroculares truncadas obliquamente para dentro; labro, mandíbulas (pretas na extremidade apical) e escapo amarelos (este um pouco escurecido para o ápice); pedicelo e os dois primeiros flagelômeros pardo-ocráceos, os restantes um pouco mais claros. Mesoscuto ligeiramente castanho com quatro listras longitudinais amarelas, um pequeno triângulo escuro no quinto anterior, entre as duas listras ântero-discais de um amarelo mais intenso. Pernas anteriores e médias inteiramente amarelas, as posteriores com os basitarsos pardo-escuros, os esporões amarelo-pálidos e as unhas com as pontas pretas. Os cinco primeiros tergos de um amarelo-castanho com faixas basais vagas mais amarelas; os dois últimos tergos mais amarelos; os esternos igualmente castanhoamarelados. Tégulas amarelo- translúcidas com mancha amarela nos dois quintos anteriores; asas fracamente lavadas de amarelo com pelinhos pretos um pouco mais adensados ao longo do bordo costal; venação e estigma amarelos.

Pilosidade pouco notável na face e dorso do tórax; no mesoscuto curtíssima, amarelento-esbranquiçada, muito densa, sem pêlos eretos; cerdas finas curtoplumosas quase brancas nas genas (até 400 micra), no vértice (até 200 micra), no escutelo (até 280 micra), no tórax aos lados e ventralmente e nos flancos do propódeo. Nas pernas pálida, porém pardo-escura na metade distal posterior das tíbias e nos basitarsos do par posterior. Os quatro primeiros tergos largamente glabros e os distais com número moderado de cerdas pálidas. Nos esternos mais notável com um tufo frouxo de cerdas na parte distal do segundo esterno com cerdas divergentes; no terceiro distalmente com pilosidade curta, plumosa, bastante densa, formando mancha esbranquiçada de contorno anterior procurvo, na 
margem uma fina franja de cerdas esparsas (cerca de 300 micra), nas extremidades laterais com numerosos pêlos um pouco mais longos, voltados para dentro; a franja do quarto esterno menos notável porém os pêlos laterais curvados para dentro mais numerosos, no quinto pouco destacada, no sexto com pêlos divergentes a partir da carena média.

Pontuação na fronte e no clípeo bastante forte, os pontos fundos, separados entre si por intervalos lisos equivalentes ao seu diâmetro, um pouco mais densa nas proximidades dos ocelos e mais esparsa na parte superior do clípeo, bastante mais fina e densa na área supraclipeal e acima dos alvéolos; mais esparsa e pouco notável nas paroculares. Fina e pilígera no mesosocuto, mais densa e sem pontos grossos intercalares; no escutelo ligeiramente mais grossa e um pouco mais esparsa; nos mesepisternos fina e esparsa com os intervalos entre dois a cinco diâmetros de ponto. Na área basal do propódeo fina, como no escutelo e metanoto, nos flancos como nos mesepisternos; fina e pilígera, muito esparsa, nos tergos largamente lisos e polidos.

Cabeça um pouco mais larga que longa; olho mais longo que duas vezes sua largura (195: 80), genas menos da metade da largura do olho (38), a face estreitada para baixo, a distância interorbital máxima menor que o comprimento do olho (140: 170: 135); malar linear (4); clípeo (88: 128: 118) e supraclipeal moderadamente abaulados; carenas paroculares convexas; uma pequena área subantenal triangular bem distinta com os lados unidos no terço inferior; a parte transversal superior do sulco epistomal bem marcada, sem formar rebordo; sulco frontal curto terminando antes do ocelo médio a uma distância maior que seu comprimento; alvéolos antenais ligeiramente acima do meio da face; distância interalveolar o dobro da alveolorbital, esta igual ao diâmetro do alvéolo (50: 26: 86: d 26); distância interocelar um pouco maior que a ocelorbital, esta igual a dois diâmetros de alvéolo (36: 40:d 20); carena preocipital aguda afastada dos ocelos por pouco mais de meio diâmetro de ocelo e das órbitas por um diâmetro. Mandíbulas bidentadas; labro em elipse transversal alongada; escapo subcilíndrico pouco mais longo que três vezes o próprio diâmetro, mais curto que a distância alveolocelar (75:22:86), pouco mais longo que um quarto do comprimento do pedicelo e flagelo juntos (288); flagelômero basal obcônico, um pouco mais curto que os dois seguintes juntos, o segundo o mais curto e o terceiro igualando o seu diâmetro, o quarto um pouco mais longo (35: 16: 20: 24:d 20). Carena pronotal aguda, forte, separada do bordo posterior, no meio, por um diâmetro de ocelo, terminando arredondada aos lados e chegando aos lóbulos em linha sinuosa. Bordo anterior dos mesepisternos em curva suave para sua porção anterior. Célula marginal 1,25 vezes mais longa que sua distância ao ápice da asa. Basitarso posterior duas vezes mais longo que largo, seu bordo anterior inerme.

A espécie à que mais se assemelha é Paratetrapedia flavipennis (Smith, 1879), descrita de Tefé (Amazonas, Brasil). Tenho um exemplar desta última espécie de Iquitos, Loreto, Peru, coletada por C.H. Dodson. Há no Museu de Zoologia da USP outro exemplar (n 96931), também coletado em Iquitos por A. Ducke em 10-VII-1906. Vi também um exemplar de Oiapoque (Amapá, Brasil), coletado igualmente por Ducke em 24-VI-1904, no extremo leste da Amazônia o 
que lhe confere extensa distribuição geográfica.

Os exemplares de Ducke foram comparados com o tipo de Smith (BMNH, Tipo: 17-B-884). Principais diferenças anotadas: em flavipennis as pernas posteriores amarelas e uniformemente amarelo- pálido-pilosas; uma mancha amarela unida ao ocelo médio descendo até o meio da fronte, aí um pouco dilatadoarredondada, terminando acima do sulco frontal; todo o mesoscuto fracamente fusco e sem vestígios de estrias longitudinais.

\section{Paratetrapedia flaviventris (Friese, 1899)}

Tetrapedia flaviventris Friese, 1899. Ann. k.k. Naturhist. Hofmus. 14 (3): 292.20)

Brasil, Santa Catarina: Blumenau, dois exemplares fêmea e macho cótipos, 1897, Virgil leg. . Designo aqui como Lectótipo a fêmea que vem descrita mais extensamente e em primeiro lugar. A fêmea está em perfeito estado, faltando apenas o artículo ungueal da perna direita trazeira. O macho foi inicialmente alfinetado na parte anterior direita do mesoscuto, porém agora o alfinete está no escutelo: falta a porção distal do basitarso anterior esquerdo e o artículo ungueal da perna média esquerda; o abdômen colado com cola transparente e também algo de cola na articulação fêmur-tíbia da perna posterior direita.

Descrição original. "Nigra, sparsim fusco-hirta, ut maculata, sed segmentis ventralibus flavis, tibiarum calcaribus albidis, tarsis fuscis, scopa fusca, metatarsorum margine posteriori albido- hirto, segmentis ventralibus 3.-4. macula triangulari impressa, fulva-tomentosa, tarsis fusco-hirtis. Tetrapedia flaviventris ist der maculata nahe verwandt, hat aber im $\sigma^{\prime \prime}$ wie $\$$ einen ganz gelben Bauch und Segment 1-2 oben mehr gelbbraun gefärbt; Hintertarsen braun, schwarzbraun behaart. 9 . Schwarzbraun, sehr sparsam dunkel behaart, wie maculata, aber am Munde mehr gelblich bis bräunlich gezeichnet, so der Clypeus, Nebengesicht und Stirnschildchen. Thorax oben ebenso matt, mit einzelnen groben Punkten. Abdomen kastanienbraun und glatt, Segment 1-3 and der Basis breit gelblich bis gelbbraun, 3-4 seitlich mit gelben Flecken, 5 mit gelber Basalbinde, die Behaarung gegen das Ende etwas länger. Ventralsegmente ganz gelb gefärbt, weisslich befranst, nach dem Ende zu werden die Fransen mehr bräunlich. Beine rothbraun, schwarzbraun behaart, Scopa aussen fast schwarz, Metatarsus am Aussenrande weiss bebüschelt und circa 1-1/2 mal so breit als die Tibie, Sporen schneeweiss. Flügel gelblich getrübt, Adern gelblich, Tegulae braun, glatt, mit matter Vorderhälfte. $10 \mathrm{Mm}$. lang. $\sigma$ wie das Weibchen, doch sind die Segmenteseiten fast alle bräunlich, das sechste fast ganz gelb, siebentes dreieckig mit Dorn, Bauch gelb gefärbt, Segmente 3-4 mit grossem, dreieckigem, eingedrücktem Fleck, der dicht sammtartig und braungelb behaart ist, die Ränder lang weiss befranst, die Befransung an der Seiten besonders long und nach inner gekrümmt. Beine schwarzbraun, ebenso und gleichfarbig behart. 10-1/2Mm. lang. Mir liegt ein Pärchen von Brasilien, Blumenau (Virgil) vor."

Fêmea. Comprimento total aproximado $9,58 \mathrm{~mm}$, da asa anterior $8,75 \mathrm{~mm}$; largura da cabeça $3,35 \mathrm{~mm}$ e do segundo tergo $3,28 \mathrm{~mm}$. 
Colorido geral da cabeça, tórax e pernas de um castanho escuro. Amarelos: o labro, largamente a base das mandíbulas, mais vagamente o terço apical do clípeo e pequena mancha supraclipeal, as paroculares inferiores estreitadas pouco acima do nível da tangente alveolar. Escapo e flagelo pardo-escuros com o pedicelo e o flagelômero basal mais escuros; pernas vagamente pardo-ocráceas com os esporões tibiais de um branco translúcido. Tergos pardo-ocráceos na base e mais escuros para a margem com manchas vagas amarelento-ocráceas aos lados do terceiro e quarto, e uma faixa basal dessa cor no quinto e sexto; segundo ao sexto esternos de um amarelo-claro, o basal mais para o ocráceo. Tégulas pardo-escuro- testáceas; asas lavadas de amarelo, com a venação até o estigma escura, o estigma e a venação apical amarelados.

Pilosidade escura muito curta na fronte, no vértice um pouco mais longa (com alguns pêlos eretos até 300 micra), no labro e terço apical do clípeo um pouco mais longa; esbranquiçada nas genas (com pêlos até 275 micra), nos meso- e metepisternos, todo lado ventral do tórax e nos flancos do propódeo; nas pernas amarelenta na face posterior das tíbias e tarsos dos dois primeiros pares, mais escura na face externa das tíbias e basitarsos posteriores, porém pálida até esbranquiçada posteriormente. No mesoscuto e escutelo curtíssima, escura, com cerdas muito curtas semi-eretas saindo de pontos mais grossos. Nos tergos pálida, quase nula nos dois primeiros, mais evidente nos seguintes principalmente para os lados e mais escura, quase preta; a franja preta marginal bastante densa e curta (até 200 micra); nos esternos com franjas premarginais pálidas.

Pontuação moderadamente grossa no clípeo, os intervalos lisos ligeiramente maiores que os pontos; mais esparsa na supraclipeal, mais fina nas paroculares, mais densa nas genas. Na fronte claramente de dois tamanhos, os pontos finos mais numerosos, ligeiramente menores que seus intervalos, os maiores mais esparsos para os lados e mais adensados para o disco e para cima junto aos ocelos; muito fina e densa nas áreas ocelorbitais, mais grossa e mais esparsa atrás dos ocelos. No mesoscuto e escutelo densíssima e muito fina deixando o tegumento quase mate, com pontos grossos esparsos, os intervalos entre os mesmos maiores que o diâmetro dos pontos; sulco médio e parápsides evidentes; nos mesepisternos lateralmente grossa e moderadamente esparsa, os intervalos lisos maiores que os pontos, estes mais finos na face anterior, para baixo um pouco mais esparsos e os intervalos lisos um pouco maiores que os pontos nos metepisternos e flancos do propódeo. Os dois primeiros tergos lisos e polidos, no segundo com alguns pontos em linha procurva marcando os limites da depressão marginal inteiramente lisa, para os lados basalmente muito esparsos; nos tergos terceiro e seguintes progressivamene mais aparente e no quinto bastante densa; as depressões marginais mais lisas demarcadas pela pontuação e com alguns micropontos para os lados apicalmente na depressão marginal do terceiro tergo, mais evidente na do quarto e formando franja esparsa e nítida na do quinto tergo. Cabeça um pouco mais larga que longa; genas de perfil mais estreitas que os olhos (65), estes um pouco mais longos que duas vezes sua largura (215: 100); face bastante estreitada para baixo com a distância interorbital máxima menor que o comprimento do olho (180: 210: 145). Clípeo, área supraclipeal e fronte bastante abaulados, o clípeo duas vezes 
mais largo que longo e mais distanciado do ocelo que sua largura; carenas paroculares vestigiais; áreas subantenais triangulares muito evidentes quase chegando à sutura epistomal. Clípeo duas vezes mais largo que longo, seu comprimento menos da metade da distância clipeocelar (72: 144: 150), os cantos látero-inferiores deprimido-rebordados; área malar linear. Distância interalveolar 1,6 vezes o diâmetro do alvéolo, a alveolocelar um pouco maior que esse diâmetro (50: 38: d 30). Carena frontal curta, inferior, seguida por uma linha mais lisa até o ocelo; distância interocelar dois diâmetros de ocelo, a ocelorbital ligeiramente maior (44: 46: d 22); carena preocipital forte, aguda, separada dos ocelos por um diâmetro de ocelo e um diâmetro e meio das órbitas (25: 32). Mandíbulas bidentadas, o dente interno um pouco maior e o bordo interno superior da mandíbula terminando numa saliência muito obsoleta, não dentiforme; labro em elipse transversal duas vezes mais larga que longa. Escapo subcilíndrico, quatro vezes mais longo que seu diâmetro, porém um pouco mais curto que a distância alveolocelar (90: 21: 100); pedicelo e flagelo juntos quase duas vezes e meia o comprimento do escapo 230); o flagelômero basal obcônico quase duas vezes mais longo que o segundo, o segundo ligeiramente maior que a metade do terceiro e este um pouco mais curto que o seu diâmetro (30: 12: 22: d 24). Pronoto um pouco abaulado, limitado por forte carena aguda, separada por um diâmetro de ocelo do bordo anterior do mesoscuto e terminando antes dos lobos pronotais. Mesoscuto normal, com o sulco médio e as parápsides evidentes, estas tão longas como dois diâmetros de ocelo; escutelo normal, um pouco inchado, as axilas pequenas; o metanoto visível desde cima; os mesepisternos com o bordo anterior arredondado passando suavemente para a face anterior, sem formar dobra ou ruga. Tégulas piriformes um pouco irregularmente estreitadas para a frente. Basitarsos posteriores duas vezes mais longos que largos, os bordos ligeiramente divergentes para baixo, o anterior inerme, o bordo distal levemente oblíquo.

Macho. Parecido com a fêmea, pardo-castanho, o abdômen ventralmente amarelo. Desenhos amarelos um pouco mais desenvolvidos: o terço anterior do clípeo no bordo superior com um pequeno recorte aos lados de uma saliência média; as paroculares até pouco acima da tangente alveolar superior, todo o labro e os três quartos basais das mandíbulas; a extremidade basal do escapo; a base dos três primeiros tergos passando gradualmente para o pardo-claro na marginal; nos outros tergos as faixas basais obsoletas, o último mais amarelento. Tégulas castanho-pardas; asas subhialinas; venação pardo-mélea até o estigma, este e a venação das células marginal e submarginais mais pálidos. Esporões esbranquiçados.

Pilosidade pouco notável como na fêmea, porém com algunas cerdas no escapo quase tão longas como o diâmetro deste; no vértice algumas cerdas até 200 micra. Geralmente preta no dorso e nas pernas, com poucos pêlos pálidos na extremidade das tíbias posteriores; branca nas genas, lados do tórax e do propódeo e na face ventral do abdômen; de resto curtíssima e bastante densa. Os pelinhos eretos no mesoscuto e escutelo muito curtos. Muito escassa nos primeiros tergos, no quarto formando franja imperfeita escura na depressão marginal, mais desenvolvida no quinto, mais densa e mais longa no sexto; cerdas longas pretas nos lados 
do quarto tergo e nos seguintes. Longa nos esternos: no terceiro um grande recorte de lados ligeiramente côncavo-convexos, truncado, anteriormente revestido de densa pilosidade pálida, especializada, de pontas escuras, as margens laterais e apical com franja branca densa, destacada, e com longos pêlos brancos láteroapicais curvados para dentro e para baixo; no quarto sem essa área denso-pilosa médio- apical mas com numerosos pêlos longos curvados para dentro e para baixo; o quinto esterno largamente glabro; o sexto com franja preta premarginal convergente para o ápice e aí mais acentuada ao longo da carena média.

Pontuação moderadamente grossa e forte; na fronte os pontos bastante uniformes, mais esparsos para cima e os intervalos lisos claramente maiores que os pontos (até dois diâmetros de ponto), mais densa e mais fina em direção ao sulco médio frontal e aos alvéolos; no clípeo e principalmente na supraclipeal bastante esparsa com alguns micropontos intercalados; nas paroculares ainda mais esparsa e sem micro-pontos; nos lados do vértice muito fina e densa deixando margem lisa junto às órbitas; progressivamente mais esparsa nas genas. No mesoscuto fina e extremamente densa, com pontos maiores muito esparsos, intercalados, porém menos evidentes que no escutelo; nos mesepisternos mais grossa e esparsa, lembrando a fronte, mais densa na área hipepimeral e bem mais esparsa para baixo e para trás. No propódeo mais fina e esparsa, na área basal bastante forte e mais densa; nos primeiros tergos quase nula; as depressões marginais, limitadas por pontos, inteiramente lisas nos três primeiros, com micropontos das franjas no quarto e quinto e alguns pontos cerdígeros no disco, mais numerosos nos tergos distais.

Cabeça mais larga que longa; face fortemente atenuada para baixo com a distância interorbital máxima um pouco menor que o comprimento do olho (192: 220: 148); este bastante mais desenvolvido que na fêmea, quase tão longo como duas vezes sua largura máxima (225: 110). Clípeo e área supraclipeal abaulados, o clípeo 1,75 mais largo que longo e sua distância ao ocelo médio pouco menos de duas vezes seu comprimento (80: 140: 155), aos lados um pouco deprimido e os cantos inferiores deprimido-rebordados; carenas paroculares praticamente nulas; distância interalveolar pouco mais de duas vezes o diâmetro dos alvéolos e a alveolorbital cerca de 1,25 esse diâmetro(55: 34:d 27); sulco frontal tão longo como quatro sétimos de sua distância ao ocelo médio, seguido por linha lisa até o mesmo, largamente obliterada; distância interocelar pouco mais de dois diâmetros do ocelo médio, praticamente igual a ocelorbital (50: 50:d 22); carena preocipital muito forte revirada aos lados, separada dos ocelos por um diâmetro e das órbitas por um diâmetro e meio de ocelo (22: 33). Labro largamente elipsóide, 1,7 vezes mais largo que longo; mandíbulas bidentadas, o dente apical bastante mais longo; escapo subcilíndrico, levemente alargado para o ápice, cinco vezes mais longo que seu diâmetro e cinco sextos da distância alveolocelar (95: 15: 110), cerca de dois terços do comprimento do flagelo e pedicelo juntos (290); primeiro flagelômero obcônico, quase duas vezes mais longo que o segundo, um pouco mais longo que o terceiro, este mais longo que seu diâmetro (30: 16: 26:d 21). Basitarso posterior tão longo com duas vezes sua largura, de lados subparalelos, seu bordo anterior com vestígios de um dentículo sub-basal. 
Tenho dois machos desta espécie de Nova Friburgo (Rio de Janeiro, BRASIL, 800m, I-1946, enviados por P. Wygodzinsky e Mello Leitão, respectivamente. Nesses exemplares o dente sub-basal do bordo anterior dos basitarsos posteriores é mais evidente que no tipo. No primeiro exemplar há uma estria amarela vaga ao longo do meio da área supraclipeal. Um outro macho de Cambuquira (Minas Gerais, Brasil), I-1941, Lopes e Gomez leg., e enviado pelo Dr. H. Souza Lopes, com os desenhos amarelos mais destacados e a estria upraclipeal mais grossa, a pilosidade esbranquiçada mais evidente na face anterior las tíbias posteriores, na extremidade distal e ao longo do bordo posterior dos basitarsos desse mesmo par; aí também com o dentículo sub-basal bem desenvolvido. Na minha coleção há mais duas fềmeas: Uma de Japuhyba, Angra-dos-Reis (Rio de Janeiro, Brasil), coletada por J. Lane e H.S. Lopes enviada pelo Dr. John Lane, e outra do Itatiaia, $815 \mathrm{~m}$, RJ, Brasil: as duas fêmeas iguais ao tipo, apenas os desenhos amarelos da face mais fracos.

Uma fêmea de São Sebastião, Praia do Barro (São Paulo, Brasil), X-1941, enviada pelo Conde A. Barbiellini ficou sem ser incluida com segurança nesta espécie, por ter todo lado ventral do abdômen bastante escuro e os esporões tibiais quase pretos. Só com mais material poderia estender-se a variação da espécie até esse nível.

\section{Xanthopedia iheringii (Friese, 1899), comb.n.}

Tetrapedia iheringi Friese, 1899. Ann. k.k. Naturhist. Hofmus. Wien. 14 (3): 296.27.

Paratetrapedia (Xanthopedia) tricolor Michener \& Moure, 1957. Bull. Amer. Mus. Nat. Hist. 112 447. Syn. nov.

Holótipo macho. BRAsil, São Paulo: São Paulo, Sellow (na etiqueta verde consta: St. Paul Sello S) n. 497, com etiqueta original de Friese/Tetrapedia iheringii n.sp., det. Friese, 1898/, a etiqueta vermelha/Type/, e outra, amareladoclara/Zool. Mus. Berlin/. O exemplar está completo, a pilosidade um pouco danificada no dorso do tórax e as pontas das asas gastas.

Diagnose original: " $\sigma$ ". Nigra, abdomine ferrugineo, pedibus flavis, sparsim griseo-hirtis; capite punctato, facie flava, antennis fuliginosis; thorace fere glabro nitidoque, pronoto, scutello metanotoque flavis; abdmine fere glabro, segmentis 2.-4. basi obscure flavo-fasciatis fere totis flavis, segmento 7. obtuso, vix prolongato. Tetrapedia iheringii steht der nasuta wohl am nächsten, hat aber gelbe Beine und das Pronotum, Scutellum und Metanotum gelbgezeichnet."

No meu trabalho com Michener (1957) consta termos três exemplares por mim anteriormente classificados como Paratetrapedia iheringii que, por falta de segurança na interpretação de Friese, descrevemos como Paratetrapedia (Xanthopedia) tricolor e que agora posso confirmar como sendo as fêmeas da espécie de Friese, colocando $P$. tricolor na sinonímia.

Macho relativamente pequeno. Comprimento total aproximado $6,5 \mathrm{~mm}$, da asa anterior $5,9 \mathrm{~mm}$ (as pontas gastas); largura da cabeça $2,28 \mathrm{~mm}$ e do segundo tergo $2,68 \mathrm{~mm}$.

Colorido geral da cabeça e tórax pretos com desenhos de um amarelo vivo: 
clípeo, supraclipeal (um pouco truncada, os cantos arredondados superiormente), paroculares inferiores até um diâmetro de alvéolo acima da tangente alveolar superior, um pouco afastadas da órbita, larga estria genal com o bordo posterior estreitado nos dois terços inferiores, o labro, os três quartos basais das mandíbulas, o escapo (atrás com estria preta), uma faixa pronotal estreita inteira, os lobos pronotais, escutelo e axilas, o metanoto, as pernas com as coxas e trocanteres parcialmente castanhos, o basitarso posterior ocráceo; os esporões esbranquiçados. Propódeo pardo-negro; o abdômen largamente amarelo com faixas pardo-acastanhadas marginais desbotadas para o bordo distal, mais evidentes do segundo ao quinto tergo. Tégulas amarelas, translúcidas do disco para os lados e para trás; as asas hialinas, a venação na metade basal mais para o amarelo e distalmente mais escura.

Pilosidade amarelo-esbranquiçada nas genas, lados do tórax e do propódeo; pálida nas pernas, porém nos basitarsos posteriores escurecida progressivamente para trás; a do abdômen branca. No vértice alguns pêlos até 250 micra, no escapo mais curtos que o diâmetro dêste; no mesoscuto formando uma penugem amarelenta, curta, entremeada por algumas cerdas mais longas; nas genas e nos lados do tórax mais longa; franjas esternais bem desenvolvidas mas sem formar as áreas denso-tomentosas típicas de Paratetrapedia.

Pontuação forte e relativamente grossa na fronte, clípeo e área supraclipeal, os intervalos lisos um pouco maiores que os pontos; nas paroculares inferiores muito esparsa e nas superiores pratica-mente nula, com pontos finos muito esparsos, mesmo nas áreas ocelorbitais e no vértice; muito esparsa e fina nas genas. No mesoscuto e escutelo apenas finos pontos pilígeros com os intervalos iguais ou ligeiramente maiores que os pontos; nos mesepisternos mais superficial e muito esparsa com intervalos lisos superando vários diâmetros de ponto. Propódeo largamente liso e brilhante com poucos pontos para os lados.

A cabeça mais larga que longa. Olhos inchados, duas vezes mais longos que largos (145: 70); área malar linear; face convergente para baixo com a interorbital superior igualando o comprimento do olho (145: 155: 110); clípeo pouco menos de duas vezes mais largo que longo e sua distância ao ocelo médio ligeiramente menor que sua largura $(58: 108: 104)$, seus cantos laterais inferiores curvo- rebordados; área supraclipeal achatada, com seu bordo anterior projetado em fina lâmina translúcida sobre a porção média da sutura epistomal; paroculares pouco inchadas sem chegar a formar carena; a distância interalveolar pouco mais de dois diâmetros de alvéolo e o dobro da alveolorbital (42: 22: d 20); fronte um pouco inchacia, com o sulco frontal curto e muito afastado do ocelo médio (cerca de dois diâmetros e meio de ocelo); distância interocelar dois diâmetros de ocelo e um pouco maior que a ocelorbital (40:35: $\mathrm{d} 20)$; carena preocipital aguda afastada dos ocelos por meio diâmetro de ocelo e das órbitas pouco mais de um diâmetro (11:24), desaparecendo em seguida; genas de perfil um pouco mais estreitas que os olhos (55). Labro curto-elipsóide, transversal ( 1,75 vezes mais largo que longo). Mandíbulas bidentadas. Escapo subcilíndrico, três vezes mais longo que seu diâmetro, porém bastante mais curto que a distância alveolocelar (55: 18: 70) e apenas um terço do comprimento do flagelo e pedicelo juntos (165); flagelômero 
basal obcônico um pouco mais longo que seu diâmetro apical, o segundo tão longo como a metade do seu diâmetro e o terceiro quase tão longo como seu diâmetro (20: 8: 16: d 18). Pronoto estreitamente elevado, sem formar carena transversal, anteriormente em plano pouco inclinado; o escutelo convexo, sem ocultar o metanoto em vista superior; aresta mesepisternal anterior suavemente arredondada; placa basitibial longa e estreita, com as margens destacadas em fina lâmina sobre a pilosidade; basitarso anterior com fina expansão posterior pouco nítida; esporões como na fêmea; basitarsos posteriores com o bordo anterior inerme. Último tergo curto- triangular, não projetado como em Paratetrapedia, apenas fraquissimamente acuminado, sem placa pigidial; os esternos sem área densopiloso-plumosa destacada, apenas com pêlos formando franjas e no quarto fortemente voltadas para dentro; o sexto esterno suavemente abaulado sem formar carena média apical.

Tenho uma segunda espécie de Xanthopedia no prelo, com colorido geral bem mais escuro. Apresenta uma certa variação, com alguns espécimens chegando a ter apenas vestígios de desenhos amarelos. Foi encontrada em grande número de exemplares pelo Prof. S. Laroca em Jaguariaíva (Paraná, Brasil), no limite sul das áreas de Cerrado.

\section{Lissopedia globulosa (Friese, 1899)}

Tetrapedia globulosa Friese, 1899. Ann. Naturhist. Hofmus., Wien, 14 (3): 298.33.

Lissopedia globulosa; Moure, 1992. Revta bras. Zool. 9 (3/4): 307.

Holótipo macho, em bom estado, ainda que faltando o último par de pernas e alguns artículos das antenas: quatro na esquerda e seis na direita. Tem as seguintes etiquetas: "495", em branco, "Brasilien Bahia Gomez S.", em verde, a etiqueta de determinação de Friese, 1898, com soletração errada: "Tetrapedia globusosa" e as etiquetas vermelha "Type" e do "Mus. Zool. Berlin".

Depois de estudar outra espécie, Tetrapedia flavopicta Cockerell, 1931, de Cichen Itza, Yucatán, México, (Lectótipo BMNH 17-B-887, no The Natural History Museum, London), fiz constar em minhas notas de viagem, em 1957, um novo gênero - Lissopedia - cuja descrição se encontra em publicação anterior (1992).

\section{Arhysoceble picta (Friese, 1899)}

Tetrapedia picta Friese, 1899. Ann. k.k. Naturhist. Hofmus.. Wien, 14: 290.17. Arhysoceble melampoda Moure, 1948. Revta Entomol. 19 (1-2): 339, Syn.n.

Arhysoceble picta ?: Moure, 1948. Revta Entomol. 19 (1-2): 340.

Paratetrapedia (Arhysoceble) picta: Michener \& Moure, 1957. Bull. Amer. Mus. Nat. Hist. 112 411 .

Estudei um exemplar enviado pelo Museu de Berlim, sem garantir tratar-se do tipo, que Friese diz ter recebido de Kriechbaumer do Museu de Munich, vindos de Fritz Müller, de Itajaí ((Santa Catarina, Brasil). É provável que o verdadeiro material típico se encontre no Museu de Munich. 
A descrição de Friese é bem detalhada, e com muitos exemplares em mãos, foi possível estabelecer a sinonímia apontada. Particularmente revelantes são as afirmativas que destaco na diagnose: "Nigra, sparsim griseo-hirta, capite abdomineque flavo-pictis, 9 scopa fusca, $\boldsymbol{\sigma}$ ( pedibus simplicibus, fusco-pilosis, abdominis segmentis ventralibus 3.-5., emarginatis, longissime albido-fimbriatis.

Vi exemplares desde Tucumán, noroeste da Argentina, até Rio Grande do Sul e Santa Catarina, Brasil.

AGRADECIMENTOS. Agradeço aos Drs. Günther Peters e Franz Koch. do Zoologisches Museum der Humboldt Universität. Berlim, o empréstimo desses exemplares, e aos Drs. E. Diller do Zoologisches Staatsammlung, Munich, e Ditter Wittmann da Universidade de Tübingen e PUC de Porto Alegre, a intermediação para poder tê-los em mãos.

\section{REFERÊNCIAS BIBLIOGRÁFICAS}

Friese, H. 1899, Monographie der Bienengattungen Exomalopsis, Ptilothrix, Melitoma, und Tetrapedia. Ann. k.k. Naturhist. Hofmus., Wien, 14 (3): 247-304.

Michener, C.D. \& J.S. Moure. 1957. A study of the classification of the more primitive non-parasitic Anthophorine bees (Hymenoptera, Apoidea). Bull. Amer. Mus. Nat. Hist. 112 (5): 395-452.

Moure, J.S. 1941. Notas sobre abelhas do grupo Tetrapedia, Klug (Hym., Apoidea). Revta Entomol., Rio de Janeiro, 12 (3): 515-521. . 1948. Notas sobre algumas abelhas de Tacanas, Tucumán, Argentina (Hymenopt. Apoidea). Revta Entomol., Rio de Janeiro, 20 (1-3): 313-346. 1992. Lissopedia, gen.n. de Paratetrapediini para a Região Neotropical, com a descrição de três espécies novas. (Hymenoptera, Apoidea, Anthophoridae). Revta Bras. Zool. 9 (3-4): 305-317.

Rolg-Alsina, A. 1990. Coelioxoides Cresson, a parasitic genus of Tetrapediini (Hymenoptera, Apoidea). Jour. Kansas Entomol. Soc. 63 (2): 279-287. 